\section{SAT0139 A MULTICENTRE, RANDOMISED, DOUBLE-BLIND, PARALLEL ACTIVE-CONTROLLED CLINICAL TRIAL COMPARING PHARMACOKINETICS, PHARMACODYNAMICS, SAFETY AND EXPLORATORY EFFICACY BETWEEN HLX01 AND EUROPE-SOURCED RITUXIMAB AS A NEW INDICATION IN CHINESE MODERATE TO SEVERE PATIENTS WITH RHEUMATOID ARTHRITIS}

Xiaofeng Zeng ${ }^{1}$, Yongfu Wang ${ }^{2}$, Zhenyu Jiang ${ }^{3}$, Zhuoli Zhang ${ }^{4}$, Lan $\mathrm{He}^{5}$, Xiao Zhang ${ }^{6}$, Xin Lư ${ }^{7}$, Xiumei Liü ${ }^{8}$, Jian Xu' ${ }^{9}$, Cibo Huang ${ }^{10}$, Rui Liu ${ }^{11}$, Xiaoxia Zuo ${ }^{12}$, Baozeng Zhao ${ }^{13}$, Wenting Qiu $^{13}$, Katherine Chai ${ }^{13}$, Xinjun Guo ${ }^{13}$, Xin Zhang ${ }^{13}$, Eugene Liu' ${ }^{13}$, Alvin Luk ${ }^{13}$, Weidong Jiang ${ }^{13}$, Scott Liu ${ }^{13}$, Pei Hu${ }^{1}$, Xia Chen ${ }^{14}{ }^{1}$ Peking Union Medical College Hospital, Beijing, China; ${ }^{2}$ The First Affiliated Hospital of BaoTou Medical College, Inner Mongolia University of Science and Technology, Baotou, China; ${ }^{3}$ The First Hospital of Jilin University, Changchun, China; ${ }^{4}$ Peking University First Hospital, Beijing, China; ${ }^{5}$ The First Affiliated Hospital of Xi'an Jiaotong University, Xi'an, China; ${ }^{6}$ Guandong Provincial People's Hospital, Guangzhou, China; ' China-Japan Friendship Hospital, Beijing, China; ${ }^{8}$ The First Hospital of Shanxi Medical University, Taiyuan, China; ${ }^{9}$ The First Affiliated Hospital of Kunming Medical University, Kunming, China; ${ }^{10}$ Beijing Hospital, Beijing, China; ${ }^{11}$ Peking University Third Hospital, Beijing, China; ${ }^{12}$ Xiangya Hospital Central South University, Changsha, China; ${ }^{13}$ Shanghai Henlius Biotech Inc., Shanghai, China; ${ }^{14}$ Beijing Tian Tan hospital, Capital Medical University, Beijing, China

Background: Biologic products, such as rituximab and adalimumab, have revolutionized the treatment for chronic inflammatory disorders, providing an option to patients who were non-responsive to conventional systemic therapies. In China, rituximab is only approved for the treatment of certain haematologic malignancies. At present, there are several approved biosimilar drugs in Europe but none in China. HLX01, a China-manufactured proposed rituximab biosimilar, was first developed for patients with non-Hodgkin's lymphoma later as a new drug for the treatment for autoimmune diseases. Currently, HLX01's biosimilar NDA for the treatment of non-Hodgkin's lymphoma is being reviewed by authorities in China.

Objectives: Evaluation of clinical PK, safety and exploratory efficacy in RA patients to support the development of HLX01 for the treatment of autoimmune disease

Methods: We conducted a multi-centre, randomised, double-blind, parallel active-controlled clinical trial to compare the PK, PD safety and exploratory efficacy (ACR2O and DAS28-CRP) between HLX01 and Europe sourced rituximab (EU-RTX) as two-1000 mg intravenous infusions (Days 1 and 15) in moderately to severely active RA patients who have had inadequate response to treatment with disease-modifying antirheumatic drugs (DMARDs). The PK equivalence was achieved if $90 \%$ confidence intervals (Cls) for the test-to-reference ratios of area under the curve from time zero to infinity $\left(\mathrm{AUC}_{(0 \text {-inf })}\right)$ and maximum observed concentration $\left(\mathrm{C}_{\max }\right)$ fall within the pre-defined $80-125 \%$ equivalence margin.

Results: In the study, a total of 196 patients randomised at 1:1 ratio to HLX01 and EU-RTX and 179 subjects (88 in HLX01 group; 91 subjects in EU-RTX group) were included in the PK pre-protocol set (PPS). The $90 \%$ confidence intervals $(\mathrm{Cl})$ for the ratio of geometric means for the pairwise comparisons of the primary PK endpoint AUC (0-inf) (Figure 1), as well as $A \cup C_{(0-14 d)}, \quad A \cup C_{(0-t, 1)}, \quad A \cup C_{(15 d-t)}, C_{m a x, 1}, C_{\max , 2}, C_{\min }$ were within the pre-specified limits of $80-125 \%$ (Table 1). Based on the ACR20 and DAS28-CRP results at week 24, HLX01 group and EU-RTX group are similar. In addition to the efficacy similarity, there was also no statistical difference in safety and immunogenicity between the two treatment groups.

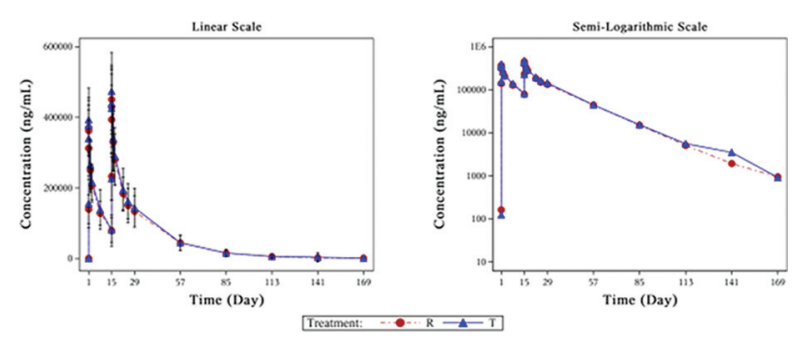

\begin{tabular}{|c|c|c|c|c|c|c|c|c|}
\hline \multirow{2}{*}{$\begin{array}{l}\text { PK parameters } \\
\text { (Unit) }\end{array}$} & \multicolumn{5}{|c|}{ Geometric mean and its ratio } & \multirow{2}{*}{$\begin{array}{c}90 \% \mathrm{CI} \\
(\%)\end{array}$} & \multirow{2}{*}{\begin{tabular}{c|} 
Inter- \\
individual \\
variation \\
$(\%)$
\end{tabular}} & \multirow{2}{*}{$\begin{array}{c}\text { Power } \\
(\%)\end{array}$} \\
\hline & $n$ & HLX01 (T) & $n$ & MabThera $(R)$ & Ratio (\%) & & & \\
\hline \multicolumn{9}{|c|}{ Primary PK variables } \\
\hline $\begin{array}{l}\text { AUC } C_{(0 \cdot \operatorname{inn}} \\
\left(\mu g^{*} / \mathrm{h} / \mathrm{mL}\right)\end{array}$ & 88 & 200753.720 & 91 & 192435.090 & 104.32 & $\begin{array}{l}96.49, \\
112.80\end{array}$ & 32.39 & 98.49 \\
\hline \multicolumn{9}{|c|}{ Secondary PK variables } \\
\hline$C_{\max , 1}(\mu g / m L)$ & 88 & 404.81 & 91 & 388.18 & 104.28 & 45 & 18.99 & $>99.9$ \\
\hline $\mathrm{C}_{\mathrm{mo}}$ & 88 & 480.35 & 91 & 464.57 & 103.40 & 3 & 20.52 & $>99.9$ \\
\hline$C_{\min }(\mu g / m L)$ & 88 & 75.09 & 91 & 71.3 & 05.20 & $\begin{array}{l}95 \\
11 \\
1\end{array}$ & 42.62 & 87.62 \\
\hline $\begin{array}{c}\text { AUC }(00 \cdot 140)^{2} \\
\left(\mu g^{*} / \mathrm{hL}\right)\end{array}$ & 87 & 50488 & 91 & 48072 & 03 & $\begin{array}{l}99.60, \\
110.75 \\
\end{array}$ & 21.64 & $>99.9$ \\
\hline $\begin{array}{c}A U C_{(0, t)} \\
\left(\mu g^{*} / \mathrm{h} / \mathrm{mL}\right)\end{array}$ & 88 & 50722.070 & 91 & 30 & 18 & $\begin{array}{l}99.74, \\
110.92 \\
\end{array}$ & 21.75 & $>99.9$ \\
\hline 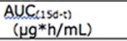 & 88 & 146631.600 & 91 & 141854.640 & 103.37 & $\begin{array}{l}93.52 \\
114.25\end{array}$ & 42.23 & 92.56 \\
\hline
\end{tabular}

Note: $T=1000 \mathrm{mg}$ HLX01 (Shanghai Henlius Biotech, Inc.); R=1000 $\mathrm{mg}$ MabThera (Roche Pharma (Schweiz)

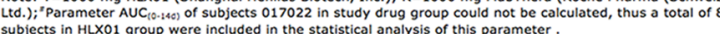

Conclusion: We report successful demonstration of similarity in PK, safety and initial efficacy between first China-manufactured biosimilar of rituximab, HLX01, and Europe-sourced rituximab in patients with moderately to severely active rheumatoid arthritis. These results support the Phase 3 confirmatory clinical trial for the development of HLX01 for the treatment of rheumatoid arthritis.

Disclosure of Interests: Xiaofeng Zeng: None declared, Yongfu Wang: None declared, Zhenyu Jiang: None declared, Zhuoli Zhang: None declared, Lan He: None declared, Xiao Zhang: None declared, Xin Lu: None declared, Xiumei Liu: None declared, Jian Xu: None declared, Cibo Huang: None declared, Rui Liu: None declared, Xiaoxia Zuo: None declared, Baozeng Zhao Employee of: Employee of Shanghai Henlius Biotech Inc., Wenting Qiu Employee of: Employee of Shanghai Henlius Biotech Inc., Katherine Chai Employee of: I am an employee of Shanghai Henlius, Xinjun Guo Employee of: Employee of Shanghai Henlius Biotech Inc., Xin Zhang Employee of: I am an employee of Shanghai Henlius Biotech,Inc., Eugene Liu Employee of: I am an employee of Shanghai Henlius Biotech,Inc., Alvin Luk Employee of: I am an employee of Shanghai Henlius Biotech,Inc., Weidong Jiang Shareholder of: I am the co-founder of Shanghai Henlius Biotech,Inc., Employee of: I am an employee of Shanghai Henlius Biotech,Inc., Scott Liu Shareholder of: I am the CEO of Shanghai Henlius Biotech,Inc., Employee of: I am an employee of Shanghai Henlius Biotech,Inc., Pei Hu: None declared, Xia Chen: None declared

DOI: 10.1136/annrheumdis-2019-eular.3669

\section{SAT0140 COMPARATIVE EFFECTIVENESS OF TOFACITINIB AND NON-TNF AGENTS SINCE 2014. IMPACT OF COMBINATION WITH METHOTREXATE}

Denis Choquette ${ }^{1}$, Louis Bessette ${ }^{2}$, Loïc Choquette Sauvageau',

Isabelle Ferdinand ${ }^{1}$, Paul Haraoui ${ }^{1}$, Frédéric Massicotte ${ }^{1}$, Jean-Pierre Pelletier ${ }^{1}$, Jean-Pierre Raynauld ${ }^{1}$, Marie-Anaïs Rémillard ${ }^{1}$, Diane Sauvageau ${ }^{1}$,

Édith Villeneuve ${ }^{1}$, Louis Coupal ${ }^{1}{ }^{1}$ Institut de Recherche en Rhumatologie de Montréal (IRRM), Rhumatology, Montréal, Canada; ${ }^{2}$ Centre de l'Ostéoporose et de Rhumatologie de Québec (CORQ), Rhumatology, Québec, Canada

Background: Tofacitinib (TOFA), a targeted synthetic DMARD, has been approved for the treatment of rheumatoid arthritis (RA) in Canada since April 2014. This oral agent preferentially inhibits signalling by cytokine receptors associated with JAK1 and JAK3 subunits. It is now indicated for the treatment of psoriatic arthritis (PsA) and ulcerative colitis (UC) since October 2018. Clinical experience with this molecule has been increasing, and questions relating to its efficacy and long-term safety are of interest. Data collection through RHUMADATA ${ }^{\circledR}$, a Quebec based clinical database and registry, allows comparison of various advanced treatment options including TOFA and non-TNFi biologic agents (i.e., agents with other modes of action - OMA) such as fusion proteins (abatacept), and IL-6 (sarilumab, tocilizumab) and CD20 inhibitors (rituximab).

Objectives: This analysis compares TOFA and OMAs used with and without methotrexate (MTX).

Methods: Data collected since January 1, 2014 (since TOFA became available in Canada) at the Institut de Recherche en Rhumatologie de Montréal (IRRM) and the Centre de l'Ostéoporose et de Rhumatologie de Québec (CORQ) was extracted from the Rhumadata ${ }^{\circledR}$ on January 7 , 
2019. The selected patients had initiated therapy with either TOFA or OMA (either without or in combination with MTX). The collected data include baseline characteristics (socio-demographic variables, concomitant and past medication, comorbidities and the Charlson comorbidity index $(\mathrm{CCl})$ ), variables measured over time (laboratory test results, patient and physician-reported outcomes, and disease activity measures such as CDAI and DAS28(4)-ESR) and persistence data (treatment duration, reason for cessation). The groups were compared to identify potential confounder, and persistence data were analyzed using Kaplan-Meier and proportional hazard methods.

Results: A total of 483 patients were initiated on TOFA $(n=162)$ or an OMA $(n=321)$ since January 1,2014 . Of those, $57 \%(n=92)$ and $59 \%$ $(n=191)$ were treated with MTX in the TOFA and OMA group respectively. These represent the first treatment following csDMARD inadequate response for 33\%(TOFA) and 29\%(OMA) of these patients. These patients had a mean disease duration of 12.1 (standard deviation=11.0) and 11.1 (10.3) years. In the TOFA group, 84\% were women, 15\% were smokers, and the mean age at treatment initiation was 57.7 (11.5). In the OMA group, $75 \%$ were women, $18 \%$ were smokers, and the mean age at treatment initiation was 57.3 (12.0) years. Patient global, pain and fatigue assessments, made on a visual analogue scale ranging from 1 to 10, were 5.6 (2.5), 5.9 (2.7) and 5.7 (2.9) in the TOFA group and 5.7 (2.5), 6.1 (2.7) and 6.0 (2.8) in the OMA group. Disease activity was assessed as moderate or high/severe in $85.9 \%$ and $88.3 \%$ of patients (DAS28(4)-ESR criteria). Among the 56 (35\%) TOFA and 149 (46\%) OMA patients ceasing therapy, reasons for cessation were "inefficacy" (TOFA: 64\% vs OMA: 59\%) and "adverse events" (TOFA: 16\% vs TNFi: $17 \%)$. Patients remaining on TOFA and OMA therapy at last follow-up had an average treatment duration of 1.7 (1.1) and 2.6 (1.4) years. No difference in retention was observed between TOFA and OMA treated patients (log-rank $p=0.6138$ ). Patients treated with an OMA+/-MTX had similar retention (log-rank $\mathrm{p}=0.2640$ ) as did patients treated with TOFA+/MTX (log-rank $p=0.9553$ ). These results remain unchanged when we adjust for age at treatment initiation, gender, disease duration, and comorbidities $(\mathrm{CCl})$ using Cox models.

Conclusion: OMA and TOFA have similar retention as do subjects treated with OMA or TOFA with or without MTX.

\section{DISCLOSURE OF INTERESTS}

Denis Choquette Grant/research support from: Abbvie, Amgen, Eli Lilly, Novartis, Pfizer, Sandoz, Consultant for: Abbvie, Amgen, Eli Lilly, Novartis, Pfizer, Sandoz, Speakers bureau: Abbvie, Amgen, Eli Lilly, Novartis, Pfizer, Sandoz, Louis Bessette Grant/research support from: AbbVie, Amgen, Bristol-Myers Squibb, Celgene, Eli Lilly, Janssen, Novartis, Pfizer Inc, Roche, Sanofi, UCB, Consultant for: AbbVie, Celgene, Eli Lilly, Novartis, Pfizer Inc, Loïc Choquette Sauvageau: None declared, Isabelle Ferdinand Consultant for: AbbVie, Amgen, Novartis, Pfizer, Speakers bureau: Amgen, Pfizer, Paul Haraoui Grant/research support from: Abbvie, Amgen, Pfizer, UCB, Consultant for: Abbvie, Amgen, Lilly, Pfizer, Sandoz, UCB, Speakers bureau: Pfizer, Frédéric Massicotte Consultant for: AbbVie, Pfizer, Janssen, Eli Lilly, Speakers bureau: Janssen, Jean-Pierre Pelletier Shareholder of: Shareholder in ArthroLab Inc., Grant/research support from: Study funded by TRB Chemedica SA, Consultant for: TRB Chemedica SA, Jean-Pierre Raynauld Consultant for: ArthroLab Inc., MarieAnaïs Rémillard Consultant for: Abbvie, Amgen, Eli Lilly, Novartis, Pfizer, Sandoz, Paid instructor for: Abbvie, Amgen, Eli Lilly, Novartis, Pfizer, Sandoz, Speakers bureau: Abbvie, Amgen, Eli Lilly, Novartis, Pfizer, Sandoz, Diane Sauvageau: None declared, Édith Villeneuve Consultant for: AbbVie, UCB, Celgene, Roche, Pfizer, Amgen, BMS, Sanofi-Genzyme, Paid instructor for: AbbVie, Speakers bureau: AbbVie, Pfizer, BMS, Roche, Louis Coupal: None declared

DOI: 10.1136/annrheumdis-2019-eular.2823

\section{SAT0141 FREQUENCY AND REASONS FOR SWITCHING BACK TO BIOLOGIC ORIGINATOR FOLLOWING INITIAL SWITCH TO BIOLOGIC BIOSIMILAR}

Rebecca Davies, Lianne Kearsley-Fleet, Mark Lunt, Kath Watson, Kimme Hyrich, BSRBR-RA Contributors Group. University of Manchester, ARUK Centre for Epidemiology, Manchester, United Kingdom

Background: Since February 2015, a number of biosimilar drugs have been introduced for treatment of rheumatoid arthritis (RA) in the UK. Biosimilars are required to have no clinically meaningful differences in efficacy or safety from the originator product. There are clear cost-saving implications when switching patients to a biosimilar; however, the longer term implications of switching have yet to be studied.
Objectives: To describe the frequency of switching back to biologic-originator (BIO-O) in patients who initially switch from BIO-O to biologic biosimilar (BIO-B), focussing on etanercept (ETA) and infliximab (INF).

Methods: The study population comprised RA subjects recruited to BSRBR-RA to 30/11/2018 who had switched from BIO-O to BIO-B (INF and ETA) and had completed at least one further study follow-up following switch. Baseline characteristics at point of switch and the proportion of patients who were recorded as switching back to BIO-O or discontinuing BIO completely following switch with reasons are described.

Results: Nine hundred and sixty six patients were included (760 switching from ETA-O; 206 switching from INF-O). After a median follow-up of 22.5 months post-switch, the majority of patients remained on BIO-B (ETA-B = $619(81 \%)$, INF-B $=166(81 \%))$. Seven percent of patients switched back to originator, with a majority following reports of ineffectiveness or feeling gen erally unwell (Table). Eleven percent stopped BIO completely, with a majority stopping for serious adverse events such as malignancy or infection. Similar results were seen for both ETA and INF. Six ETA and 3 INF reported injection or infusion related reactions following switch $(0.9 \%$ overall) leading to switch back (4 ETA) or biologic discontinuation (2 ETA/3 INF). Conclusion: Data from this study show that the majority of patients who switched from BIO-O to BIO-B remain on the biosimilar over the short term. A small proportion of patients have switched back to the originator drug with the majority doing so for reports of ineffectiveness rather than safety concerns. Hypersensitivity reactions, such as infusion reactions were rare reasons to stop either drug completely or switch back to originator.

Table 1

\begin{tabular}{|c|c|c|}
\hline & \multicolumn{2}{|c|}{ Patients Switching from O to B } \\
\hline $\bar{N}$ & \multicolumn{2}{|l|}{966} \\
\hline Etanercept & \multicolumn{2}{|l|}{$760(79)$} \\
\hline Infliximab & \multicolumn{2}{|l|}{$206(21)$} \\
\hline Age, years & \multicolumn{2}{|l|}{$66(56-72)$} \\
\hline$\%$ Female & \multicolumn{2}{|l|}{75} \\
\hline Disease duration, years & \multicolumn{2}{|l|}{$20(13-28)$} \\
\hline DAS28 score & \multicolumn{2}{|l|}{$3.2(2.2-4.2)$} \\
\hline Time on BIO-O before switch years & \multicolumn{2}{|l|}{$11(3-13)$} \\
\hline Follow-up time after switch, months & \multicolumn{2}{|l|}{$22.5(16-25)$} \\
\hline $\begin{array}{l}\text { Patients switching back or stopping } \\
\text { biologic }\end{array}$ & $\begin{array}{l}\text { BIO-B to BIO-O Switch } \\
\text { back }\end{array}$ & $\begin{array}{l}\text { Stop all } \\
\text { BIO }\end{array}$ \\
\hline $\mathbf{N}$ & 71 & 104 \\
\hline Time to switch back or stop, months & $5(3-8)$ & $7(4-12)$ \\
\hline Ineffectiveness & 38 & 24 \\
\hline Adverse event & 18 & 56 \\
\hline Drug hypersensitivity/infusion reaction & 4 & 5 \\
\hline Infection & 0 & 12 \\
\hline Malignancy & 0 & 14 \\
\hline Generally unwell & 8 & 2 \\
\hline Other $A E^{\star}$ & 2 & 20 \\
\hline$A E$ unknown & 4 & 3 \\
\hline Patient decision & 2 & 1 \\
\hline Remission & 0 & 4 \\
\hline Unknown & 13 & 19 \\
\hline
\end{tabular}

All values are median (IQR) or $\mathrm{n}(\%) .{ }^{*}$ Other adverse events include those that are unique events per patient

Disclosure of Interests: Rebecca Davies: None declared, Lianne KearsleyFleet: None declared, Mark Lunt: None declared, Kath Watson: None declared, Kimme Hyrich Grant/research support from: Grants to institution: BMS, Pfizer, UCB

DOI: 10.1136/annrheumdis-2019-eular.6845

\section{SAT0142 DIFFERENCES IN PATIENT CHARACTERISTICS AND PATTERNS OF TREATMENT BY DISEASE-MODIFYING ANTIRHEUMATIC DRUGS (DMARD) IN BDMARD NAIVE VERSUS EXPERIENCED PATIENTS}

Robin K. Dore ${ }^{1}$, Leslie Harrold ${ }^{2,3}$, Taylor Blachley ${ }^{3}$, Kelechi Emeanuru ${ }^{3}$, Jenya Antonova ${ }^{4}$, Joel Kremer ${ }^{3,5}$. '1Private Practice, Tustin, United States of America; ${ }^{2}$ University of Massachusetts Medical School, Worcester, United States of America; ${ }^{3}$ Corrona, LLC, Waltham, United States of America; ${ }^{4}$ Gilead Sciences, San Francisco, United States of America; ${ }^{5}$ Albany Medical College, Albany, United States of America

Background: For RA patients (pts), EULAR and ACR recommend various DMARDs. Available treatments have short durability and low persistency. Understanding differences between patients who initiate DMARDs as 